\title{
Public Knowledge and Attitudes towards Climate Change and Its Impacts on Ecosystems in Grenada
}

\author{
Lindonne Glasgow ${ }^{1}$, Benny Langaigne ${ }^{2}$, Carisha Thomas ${ }^{2}$, Olando Harvey ${ }^{3}$, Ezra Angella Campbell² \\ ${ }^{1}$ St. George's University, St. George's, Grenada \\ ${ }^{2}$ Grenada Community Development Agency, Gouyave, St. John, Grenada \\ ${ }^{3}$ Ministry of Agriculture, Lands, Forestry, Fisheries and the Environment, St. George's, Grenada \\ Email: linglasg@yahoo.com
}

How to cite this paper: Glasgow, L., Langaigne, B., Thomas, C., Harvey, O. and Campbell, E.A. (2018) Public Knowledge and Attitudes towards Climate Change and Its Impacts on Ecosystems in Grenada. American Journal of Climate Change, 7, 600-610.

https://doi.org/10.4236/ajcc.2018.74037

Received: August 26, 2018

Accepted: November 16, 2018

Published: November 19, 2018

Copyright $(9) 2018$ by authors and Scientific Research Publishing Inc. This work is licensed under the Creative Commons Attribution International License (CC BY 4.0).

http://creativecommons.org/licenses/by/4.0/

\begin{abstract}
Objective: This study was conducted to assess knowledge and attitudes to climate change and coastal and marine ecosystems of residents in the westerly parishes of St. Mark and St. John in Grenada. Methodology: Interviews were conducted in focus groups with three distinct groupings of fishers, students, and community members. The interviews focused on seven thematic areas: knowledge and awareness about climate change; components of the coastal and marine ecosystems; impact of climate change on the ecosystems; marine protected areas; attitude to climate change and impacts; responses to climate change and impacts; and education and sources of information. Results: The participants discussed their observations of major changes in the coastal and marine environments including considerable build-up of sediments along the shoreline due to the erosion of soil from inland, smaller volume of rivers, increased severity and frequency of flooding, larger deposition of sand in reefs, decline in the stock and variety of fishes, and erosion of coastal lands. The students were more knowledgeable about factors that contributed to climate change but had doubts about how they contribute to the problem and whether the community was willing to take action to protect the environment. The fishers were more knowledgeable about changes in the environment and advocated for the designation of marine protected areas (MPAs) to protect their trade. The community residents were the least knowledgeable about climate change. The community residents, however, felt that education was necessary to effect positive change towards the coastal and marine ecosystems. The fishers and community members demonstrated a high level of interest and support for MPAs. Conclusion: The findings highlight a need to address gaps in knowledge of all groups about the potential effect of climate change on the
\end{abstract}


environment. Such knowledge is also necessary to build community support for the MPA project.

\section{Keywords}

Grenada, Climate Change, Marine Protected Area, Marine Ecosystem

\section{Introduction}

Climate change is a global challenge that affects countries in different ways. In many countries, the effects of climate change are already pervading most of the major productive and developmental sectors. Low- and middle-income countries are especially vulnerable to the effects of climate change owing to limited financial and technical capacities to adopt alternative technologies, monitor population practices and to implement strategies to mitigate the effects of the phenomenon [1] [2]. Additionally, many countries continue to lack policies to support adequate responses to address the problem.

Coastal and marine ecosystems face many threats from the changing climate. As the issue becomes more prominent, countries have been taking steps to protect natural resources, settlements, and livelihoods. Several studies have been conducted throughout the wider Caribbean region, including Jamaica, Grenada, Guyana, St. Lucia and Belize to assess knowledge and practices related to management of the resources as well as responses to the impacts and coping strategies [3]-[8]. Such studies also produce evidence to inform strategies aimed at addressing the environmental issues.

Caribbean countries such as Belize, Jamaica, St. Lucia and Guyana have suffered the consequences of inadequate management of their coastal and marine resources; namely, mangroves, reefs and fish stocks [2]. Poor management of the resources and inability to mitigate the impacts of climate change has significant implications for settlements, socio-economic activities and biodiversity, especially in the Caribbean region where approximately $70 \%$ of the population are settled in coastal areas [9] [10].

Grenada is a small tri-island State located in the southern end of the Caribbean. The Caribbean Sea lies on the western side of the island and the Atlantic Ocean on the eastern side. Changes in the weather patterns have also impacted the natural coastal and marine ecosystems in Grenada. Additionally, human-environmental interfaces have facilitated the transfer of the effects to the social and economic systems of the communities. Noting the replication of the problem, Day [2] stated, "Grenada's coastal communities are particularly at risk from the combined hazards of sea level rise and intensifying storms, which present real and increasing threats to human life and infrastructure in low-lying areas. These hazards are greatly exacerbated by the degraded condition of many 
of Grenada's coastal ecosystems, particularly mangroves and coral reefs, which, in a healthy state, can provide effective barriers for coastal protection and disaster risk reduction." ([2], p. 72)

This study, which was conducted to explore awareness, attitudes, and responses of residents in the parishes of St. Mark and St. John, forms part of a larger Caribbean Community Climate Change Centre (5Cs) project implemented by the Grenada Community Development Agency (GRENCODA). More specifically, the Community-based Coastal Ecosystem Management for Climate Adaptation in Selected Areas of Grenada Project aims to foster the creation of effectively managed marine protected areas (MPAs) on the west coast and to increase public awareness of and community resilience to the adverse impact of climate change. The findings of the study will contribute to informing the project strategies for community awareness and participation; thereby, improving the management of the coastal and marine resources in the parishes. The Parishes of St. John and St. Mark are located along the western coast of Grenada. The two parishes are largely dependent on fishing and other marine-related activities for livelihood and subsistence.

\section{Methodology}

The design of this study follows a phenomenological research model aimed at understanding awareness, attitudes, and responses to climate change and coastal and marine ecosystems. The data collection for this study was via three focus group sessions with participants from the parishes of St. Mark and St. John.

Three focus group sessions were conducted in December, 2018; one with each of the primary target groups (i.e. students, fishers and community residents). The participants were carefully selected to facilitate a robust phenomenological study through representation and to ensure gender balance. Group sessions were conducted with 7 students ( 3 males, 4 females), 3 fishers ( 3 males), and 8 community residents ( 4 males, 4 females). The students were in the age group $14-16$ years and in the upper forms in the secondary school. This group was considered as appropriately to participate in discussions about climate change and representing the perspectives and knowledge of the broader student body. The selected fishers were involved in the fishing trade for at least 10 years. The community residents were selected based on leadership and involvement in community-based activity. The demographics of the groups allowed for comfortable settings to encourage participation. Informed consent was secured from adult participants and from parents of students before participation in the discussions.

In developing the guiding and probing questions, several studies were reviewed including climate change related studies conducted in Jamaica, Grenada, Guyana, St. Lucia and Belize [3]-[8]. Those documents provided information about potential themes and questions that could be included in this study. Questions that were considered appropriate were adopted and modified, as necessary, 
to fit the local context. The questionnaire was the piloted with the surveyors who also resided in the communities. The surveyors provided feedback on clarity of the questions and suggestions for modifications to improve clarity of the questions for the community residents.

The focus group discussions were facilitated by a trained facilitator. Each session was conducted for about two hours. The discussions focused on 7 thematic areas: knowledge and awareness about climate change; identification of components of the coastal and marine ecosystems; awareness of impacts of climate change on coastal and marine ecosystems; knowledge of MPAs; attitude to climate change and impacts on coastal and marine ecosystems; responses to climate change and its impacts on coastal and marine ecosystems; and education and sources of information about climate change and coastal and marine ecosystems management.

The discussions were recorded for accurate transcription while notes were also taken by a designated scribe in each session. The responses were organized by the thematic areas. The information was also manually analyzed to describe awareness, attitudes, and responses by participants within and between the groups. A validation workshop was also conducted with the participants to review the initial report and to make modifications to more accurately reflect the participants' responses.

\section{Results}

\subsection{Knowledge about Climate Change}

Participants referred to climate change as changes in the weather. Some participants connected the term to changes in the environment, such as changes in the sea, rivers and adverse events. In each group, the participants related climate change to the direct actions of humans. One community member emphatically stated, "We are the cause of climate change!" The participants also named pollution, increased level of carbon monoxide in the atmosphere, mining, increased use of technology and the excessive use of agro-chemicals as contributors to climate change. In each group, participants also identified the impact of climate change as increased frequency and intensity of hurricanes, sea-level rise, increased flooding, melting ice at the poles, as well as a rise in temperatures. The participants, however, were unable to give details about how climate change caused these events. When probed about what would happen if the issue was not addressed, one student stated, "More lives would be lost!" The fishers expressed concern about the loss of lands due to wave actions, pollution of the sea, and also expressed that there was a need for funds to build sea-defence walls.

\subsection{Knowledge about Coastal and Marine Ecosystems}

In each group, participants were readily able to name the most obvious components of the coastal and marine environments on the western side of the island. Beach vegetation, fishes, and corals were named while features that were common 
mostly on the eastern side of the island, such as mangroves and coastal lagoons, were not named. As to the benefits of the coastal environment, a participant in the fishers group stated, "It sent my children to schoo!" One student stated that the coastal environment benefits tourism as it brings foreign exchange to the communities. The value of the coastal and marine resources for food, to generate employment, protection for land during storms, as well as recreation and leisure, were also stated. When probed about the value of mangroves, the fishers were mostly able to connect the resource with reproduction and habitat for fishes. One community member stated, "The mangroves are the maternity wards for the fish," A participant in the fishers group noted, "The healthier the mangroves, the greater the fish stock." One student responded, "The fishes live in the mangroves and coral reefs, it is their habitat."

\subsection{Awareness of the Impact of Climate Change on the Coastal and Marine Ecosystems}

Participants stated that the coastline was different to how it was known years ago and they attributed this difference to climate change. They indicated that along the Gouyave coastline, there is a considerable build-up of sand on the shoreline. The fishers explained that this was due to the erosion of soil which washed down in the rivers. One fisherman explained that the fish stocks have declined significantly. Another fisherman noted that there was little coral reef left. This viewpoint was expressed by participants in each group. The participants also observed that the volumes of rivers were much smaller, there was a drastic increase in the severity and frequency of floods and it took a shorter time for Gouyave town to be flooded. It was noted that there was a significant loss of beach vegetation in areas, such as Palmiste and White Gate. The fishermen explained that much of the loss of vegetation in these areas was due to excessive de-bushing. The fishermen stated that the build-up of sand over the reefs and rocky areas contributed to a reduction in the fish stocks and that this had a negative impact on their livelihood. The increase in frequency and intensity of flooding in-land was associated with the destruction of the coral reefs. The fishermen saw these changes as evidence of climate change. The community members stated that the entire coastline had undergone significant changes which negatively impact the fishermen and the wider community. They indicated that the beaches were badly eroded in some areas, while in other areas, the reefs were completely covered by sand. It was also noted that there was very little beach vegetation left. Some students agreed that climate change had a direct impact on the coastal and marine environment while others disagreed and or were unsure of whether it had an impact or not. The students stated that the warmer waters were causing coral bleaching, the stronger hurricanes were causing more significant damage to the coastal areas and the beach areas were contracting. They indicated that the changes affected their recreational activities and was also responsible for the loss of revenue from tourism. 


\subsection{Attitude to Climate Change and Impacts on Coastal and Marine Ecosystems}

The participants expressed a sense of loss, sadness, and despair in relation to climate change and the impacts on the environment. One student stated, "I feel sad but I feel like I have some power to make a change." Another felt helpless because he thinks his voice would not be heard if he speaks out about the issues. A student remarked, "I feel concerned about the situation. The one place I like is the beach and that is being destroyed. There could be something done but at the end of the day it's about changing our lifestyles and we don't want to change our lifestyles." Another remarked, "I wasn't really concerned or even paying attention to these issues before. Right now we have to be more mindful of the situation. The majority of my community does not really care about climate change so I cannot really do anything." Another student stated, "Even though we introduce laws and other measures to address climate change, at the same time the use of technology contributes to climate change. So, if we really decide to make an impact on climate change we would be going back to the Stone Age. No one wants to change their lifestyle to save the planet. We all want to live a happy lifestyle. It does not matter whether you put laws in place, so we need to assess the situation and what we can do is slow down climate change but it will still be a problem." Fishers remarked, "The oil being used during the carnival is a bigger problem than we realize." Another stated, "I'm sad and I'm angry; I've not gone out for the last three months! I have my boat on the sand because it doesn't make sense when you have to get bait and buy fuel and you're only catching one tuna, one ocean gar... you're not making anything!" A community member remarked, "I feel deprived!"

Some participants in each group felt that they had personally contributed in some way to the degradation of the coastal and marine environments. The fishers stated that the issue of pollution, including washing used motor oil on beaches after carnival activities, contributed to the degradation of the coastal and marine environments. Some students stated they were unsure about whether they contributed to the problem, although the students acknowledged that they littered. The students did not make a connection between littering and impacts on the coastal environment.

The participants indicated their willingness to protect the coastal and marine environments and to become involved in projects to address the issues. The participants also expressed interest in learning how to protect the coastal ecosystems. One community member extended an open invitation to utilize his personal resources for the dissemination of information. One fisher stated, "Yes, we are willing to become involved in the projects." Another stated, "We have to start somewhere!"

\subsection{Responses to Climate Change and Impacts on Coastal and Marine Environments}

The participants recommended the following measures to mitigate climate 
change impacts on coastal and marine environments: implement laws to protect the coastal and marine ecosystem, educate the general public about climate change and coastal and marine ecosystem, implement measures to deal with the pollution and runoff from the land into the sea, increase garbage removal services to combat pollution and introduce proper de-bushing methods to reduce soil erosion. The students felt that the introduction of laws and education programmes can have a positive impact on behaviours. One student, however, explained, "Laws will be more persuasive in dealing with climate change than education because if the law is broken something bad will happen to them." The students also believed that parents should be educated. The community members stated that efforts should be made to educate everyone in the population. The participants suggested community groups, law enforcement officers, public sector workers, students, the general public, fisher folks, traffickers and the private sector should be involved in mitigation efforts.

Although the students and fishers were unsure of how they could contribute specifically to mitigation, the members of the community group suggested that they can be designated ambassadors or form a watch-dog group to help effect change. The community members also recommended clean-up campaigns, collection of sorted garbage and special programmes to decrease pollution. Some students indicated that although the community should be involved in the mitigation programmes, they were not sure how the community should be involved. The students also indicated that they did not believe the community groups would show interest in doing anything to effect change.

\subsection{Knowledge about Marine Protected Parks}

In each group, the participants had a good understanding of MPAs. They described MPAs as fish nurseries and safeguarded areas. One participant stated

"Money in the long term! I understand the long-term benefit of having a marine protected area." Most of the participants stated that they were first introduced to the concept of MPAs with the designation of such areas in Molinere-Beausejour. Some participants stated that they learned about MPAs from posters or they heard family and friends discussing the subject. Two students indicated that they were provided with information about MPAs between October and November of the current year by persons conducting a baseline survey for GRENCODA's project. One student stated that the information was not very useful and the other stated that the information was new and, as such, very useful. After being informed about the Project, the students expressed keen interest in supporting the initiative. One student indicated that designating MPAs would help fishers to be aware of the need to manage the resources and control the problem of overfishing.

The fishermen suggested that the MPA should extend from the area next to the Gouyave Fish Market to Gross Point in St. Mark on the north side of Gouyave town and from the Cuthbert Peters Park area to the White Gate Point on the south side of Gouyave town. The fishers noted that these areas contained 
reefs which needed to be protected. Participants in the community focus group also suggested that the group be transformed into an action group to assist in dissemination information and monitoring the community's responses to the MPA project.

\subsection{Sources of Information about Climate Change and Coastal and Marine Ecosystems}

Most of the participants stated they obtained information about climate change and the management of coastal and marine resources from radio and television. Some of the participants also stated they received a limited amount of information from the Fisheries Division in the Ministry of Lands, Forestry, Fisheries and the Environment. The community members stated they also gathered information from documentaries, while the students stated they received information from the school. One student stated, "The impact of climate change on the lives of people must be addressed." A community member recommended that special emphasis be placed on creating public awareness about the necessity and benefits of sustainable household and farming practices. The participants suggested that the following media be utilized to disseminate information about climate change and the protection of marine and coastal environments: face to face conversations, infomercials on television and radio, theatricals, workshops, flyers and posters, local celebrities, social media, mass text messages and newspapers.

\section{Discussions and Conclusion}

The information that was collected in this study was, generally, consistent with the findings from previous studies that were conducted in Grenada and in other countries. The studies by Fontenard [3] and Isaac [5] show that knowledge and/or practices were somewhat short of the standards for adequate awareness and management of climate change impacts and coastal and marine resources. Similarly, the studies that were conducted in St. Lucia, Jamaica and Belize also show some inconsistencies in knowledge and practices [6] [7] [8] [11]. The results from this study indicate that the participants were aware of climate change and its effects on the environment. Nonetheless, there was less clarity about how or why the impacts occurred. This gap in knowledge should be addressed to instil an appreciation for the science of climate change. Such knowledge will also raise awareness about the potential impact of human behaviours on climate change and what can be done to combat or mitigate these impacts.

Generally, the students were more knowledgeable about the factors that contributed to climate change and the consequences while the fishers were more knowledgeable about MPAs and the benefits that can be derived from coastal and marine resources. The community residents appeared to have the lowest level of knowledge, however, the residents felt that education was necessary to effect positive change in the communities. These findings also demonstrate how routine activities may influence interest and the level of knowledge that is acquired. Nonetheless, management of MPAs and other natural resources require 
consistent and deliberate actions by all segments of the population. The findings highlight the need for comprehensive education programmes in the parishes. The vulnerability of coastal communities in Grenada and the urgency for action was also highlighted by Day [2].

The participants were very aware of changes in their environments. Despite these indications, the students disagreed on whether climate change was responsible for some of the impacts on the environment. Again, this demonstrates the need for a cross-cutting education and sensitization programme to address nuances. While there are still doubts that climate change occurs, the scientific community has put forward much evidence to prove that there are sustained changes in the weather pattern and those changes also impact on the environment. The findings in this study may, however, indicate a widespread problem with the lack of information and clarity about climate change and its effects. This problem should be addressed using a systems thinking approach, involving multi-sectored collaboration and action.

Another key area for attention is to increase knowledge about the components of the coastal ecosystem and the interplay between the components. In-land activities, for example, can have serious implications for the health of the coastal environment. Nonetheless, participants were not very knowledgeable in identifying the components of the coastal environment. The components that characterize the western side of the island were the only ones that were named. Across the sessions, there were very little discussions about mangroves, coastal lagoons, and even rivers. This apparent gap in knowledge can have implications for practice. Residents may have fewer concerns about things that they do not perceive as contributing directly to their welfare. Sensitization campaigns should use an ecosystem-based approach to heighten awareness about the connectivity and value of each part of the ecosystem.

The recommendation that was made by the participants to form a community action group is noteworthy. This may reflect a sense of ownership and responsibility for managing the community resources. The fishers and community residents were very vocal in expressing their anger and frustration over the degradation of the community resources. On the other hand, the students expressed little optimism for community groups to become involved and be effective in bring about change. The differences in the sentiments of the groups may be indicative of the potential interest and involvement by individuals in different age groups. A follow up study may be necessary to further investigate differences in the attitudes of individuals across different age groups. This measure may also provide a critical opportunity to identify and address concerns by different groups about the project. Meanwhile, however, GRENCODA should leverage the interest that was displayed to galvanize support and participation in the MPA project.

While the findings from this study can be used as baseline information, consideration should be given to conduct ongoing assessments to identify changes in knowledge and/or practices, particularly following the establishment of the MPAs. Such studies would be necessary to inform modification of strategies to 
improve management of the resources. The ongoing quantitative study is one vital step to validate some of the information that was collected in this qualitative study. More importantly, the quantitative study provides an opportunity to engage a wider cross-section of the community and to generate data and information that is more generalized to the population.

In conclusion, this study provides useful information about the strengths and gaps in knowledge, attitudes, and practices of residents in the parishes of St. John and St. Mark with regard to the climate change and coastal and marine environments. The results highlight a need to address gaps in the level of knowledge across all groups particularly in relation to the science of climate change, the interplay between components of the environment, and the potential social and economic impacts on communities. Such knowledge is also necessary to influence positive social change and to build community support for the MPA project.

\section{Acknowledgements}

The following persons and institutions are acknowledged for their support and contributions to this study: Caribbean Community Climate Change Center (5Cs); the German Development Bank (KfW); Ms. Amanda Boldeau-Grenada Community Development Agency; Principal and students-St. Rose Modern Secondary School; Principal and students-St. Mark's Secondary School; Executive and members of Gouyave Fishermen Cooperative Society Ltd. Executive and members of St. Mark's Fisheries Office; Ms. Hayley Crandell-Department of Public Health and Preventive Medicine, St. George's University; Mr. Crafton Isaac-Ministry of Agriculture, Forestry and Fisheries.

\section{Conflicts of Interest}

The authors declare no conflicts of interest regarding the publication of this paper.

\section{References}

[1] Sem, G. (2007) Vulnerability and Adaptation to Climate Change in Small Island Developing States.

https://unfccc.int/files/adaptation/adverse_effects_and_response_measures_art_48/ application/pdf/200702_sids_adaptation_bg.pdf

[2] Day, O., Van Proosdij, D., Campbell, D., Lee, S., Baker, G. and Thomas, J. (2016) Building Capacity for Coastal Ecosystem-Based Adaptation in Small Island Developing States. http://www.lumbadive.com/fotosite2014/BCCEbA-SIDS.pdf

[3] Fontenard, T. (2016) UNDP-JCCCP In-Country Specific Campaign for Grenada: Results of Climate Change Awareness Survey. http://www.adaptation-undp.org/sites/default/files/resources/climate_change_kap_ survey_report_grenada_0.pdf

[4] Hope, S. (2016) Knowledge, Attitudes \& Practices Study on Climate Change Adaptation \& Mitigation in Guyana.

http://www.adaptation-undp.org/sites/default/files/resources/climate_change_kap_ survey_report_guyana_0.pdf 
[5] Isaac, C.J. (2010) An Evaluation of Socio-Economic Conditions and Environmental Interactions on a Section of the East Coast of Grenada.

http://www.socmon.org/upload/documents/Isaac\%202010\%20east\%20coast\%20Gre nada\%20SocMon\%20CTR\%2027.pdf

[6] Jamaica Climate Change Enabling Activity (JCCEA) Project (2005) Jamaica Climate Change Kap Study.

http://research3.fit.edu/sealevelriselibrary/documents/doc_mgr/473/Jamaica_Public _\&_Climate_Change_-_JCCEA_2005.pdf

[7] Planning Institute of Jamaica (2012) Appendices for the Report on Climate Change Knowledge, Attitude and Behavioural Practice.

http://www.adaptation-undp.org/sites/default/files/resources/climate_change_kap_ survey_report_grenada_0.pdf

[8] Severin P. and Small, B. (2016) Knowledge, Attitude, Practices, Behaviour Study on Climate Change: Saint Lucia Baseline Study 2016.

http://www.adaptation-undp.org/sites/default/files/resources/knowledge_attitude_p ractices_behaviour_kapb_study_on_climate_change_st.lucia_final.pdf

[9] Commonwealth Marine Economies Programme (2017) Caribbean Marine Climate Change Report Card 2017.

https://www.coastalzonebelize.org/wp-content/uploads/2017/04/Caribbean_Report _Card1.pdf

[10] United Nations Environmental Programme (2008) Climate Change in the Caribbean and the Challenge of Adaptation.

http://www.pnuma.org/deat1/pdf/Climate_Change_in_the_Caribbean_Final_LOW 20oct.pdf

[11] Belize Marine Conservation and Climate Adapptation Project (2016) Knowledge, Attitude, and Practice Survey Consultancy-Belize.

http://www.fisheries.gov.bz/wp-content/uploads/2018/07/MCCAP-KAP-Survey-FI

NAL-Report.pdf 